\title{
VENTRICULAR SEPTAL DEFECT SIMULATING PATENT DUCTUS ARTERIOSUS
}

\author{
BY
}

\section{T. J. DANARAJ}

From the Department of Medicine, University of Malaya

The continuous machinery murmur heard over the pulmonary area is generally evidence of a patent ductus arteriosus, but there are exceptions when the murmur is due to congenital aortic septal defect (Gross, 1952; Gasul et al., 1951), to perforated aortic sinus into the right ventricle (Jones and Langley, 1949; Wood, 1950), or to rupture of an aortic aneurysm into the pulmonary artery (White et al., 1941; Porter, 1942).

The case reported below with a high ventricular septal defect just below the aortic valve, complicated by aortic regurgitation from distortion of an adjoining valve cusp, provides another example. This combination was described by Laubry and Pezzi (1921) and Laubry et al. (1933). In describing Eisenmenger's complex, Taussig (1947) stated that the aortic cusp which lies above the ventricular septal defect is often abnormally large and deep and sometimes at a lower level than the other two cusps; aortic insufficiency frequently occurs and at necropsy a scarred valve is found.

The adjoining cusp may herniate into the right ventricle through the ventricular septal defect giving rise to severe aortic incompetençe and a clinical picture resembling a patent ductus. Such cases were recorded by Allen (1941), Hurst and Schemm (1948), and Soulié et al. (1949). Ash and Murphy (1950), Ascenzi et al. (1951), and Baylis et al. (1955) recorded cases having similar clinical features where the aortic cusp had herniated through the defect into the right ventricle. Some patients in whom a high ventricular septal defect lay in such a position that the medial cusp of the aortic valve was incompletely supported, and hence collapsed from time to time giving rise to aortic insufficiency, have been noted by Gross (1953). In reporting 60 cases with isolated ventricular septal defect, Wood et al. (1954) diagnosed two more with marked aortic incompetence, one of which died suddenly and was found to have a deformed anterior aortic cusp which had partly prolapsed into the defect of the ventricular septum. Several of these authors concluded that the syndrome of ventricular septal defect with aortic incompetence is apt to be mistaken for a patent ductus and may lead to a profitless and dangerous operation.

\section{Case Report}

A Chinese girl, aged 14 years, was admitted to the General Hospital, Singapore some hours after the onset of severe retrosternal pain which had come on suddenly that day. While alighting from a bus on her way home from school, she suddenly developed severe gripping pain behind the sternum which radiated upwards to both sides of the neck and downwards along the inner side of the left arm, and difficulty in breathing. She managed to walk the few yards home and went to bed. There was no history of similar attacks in the past; her previous health was good and her parents were not aware of the presence of any heart disease prior to this admission.

Physical examination showed a well-built young girl who appeared to be in a state of shock from severe pain. She was pale and breathless, with a cold clammy skin; the pulse which was collapsing in character was rapid but regular at 150 a minute. The systolic blood pressure was $84 \mathrm{mg}$. $\mathrm{Hg}$ but the diastolic pressure was not obtainable, the sounds remaining audible until the pressure reached zero. There was no cyanosis and no visible pulsations in the neck. The cervical veins were not engorged and there was no odema.

The apex beat was felt $10 \mathrm{~cm}$. from the midline in the fifth left intercostal space and was not forceful. In the second left intercostal space parasternally a continuous thrill, which filled the whole of systole and 
diastole, was easily felt. Over the same area a loud, rough, and continuous "machinery" murmur with systolic accentuation was heard; it was transmitted over the entire præcordium and obscured both heart sounds. Examination did not reveal any other abnormality.

The diagnosis made at this stage was of patent ductus arteriosus, but the retrosternal pain was difficult to explain and was thought to be due to cardiac ischæmia resulting from paroxysmal auricular tachycardia. This, however, was not substantiated by the electrocardiogram which showed a sinus tachycardia of 150 a minute and left ventricular strain. She showed no response to treatment and died eight hours after admission to hospital.

\section{Necropsy}

Careful dissection failed to disclose a patent ductus and no ligamentum arteriosum was found.

The heart weighed $150 \mathrm{~g}$. and was not generally enlarged though there was slight hypertrophy of both ventricles. Directly below the attachment of the anterior aortic cusp was a circular ventricular septal defect, about $1 \mathrm{~cm}$. in diameter, which was almost completely occluded by a pouch-like dilatation of the base of this cusp (Fig. 1). The pouch, which also measured about $1 \mathrm{~cm}$. in diameter, had collapsed and protruded through the septal defect appearing in the right ventricular cavity as a thin membrane just below the pulmonary valve (Fig. 2). A rupture of this pouch at its apex was demonstrated by passing a probe through it from the left to the right ventricle. The trivial resistance offered by this displaced cusp to the column of blood returning in diastole must have resulted in gross aortic insufficiency. None of the cusps showed any evidence of sclerosis or of bacterial endocarditis: there was no widening of the commissures nor dilatation of the aortic ring. The orifice of the right coronary artery was higher than usual being above the level of the upper border of the deformed cusp; both coronary vessels were patent. The other valves and the aorta and pulmonary artery showed no abnormality. Examination of the lungs, liver, kidneys, and spleen showed only congestive changes. The skull was not opened.

\section{Discussion}

The diagnosis of patent ductus arteriosus is made with a high degree of accuracy by the detection of a continuous machinery murmur over the pulmonary area but in 4 of the cases quoted thoracotomy for ligation of a patent ductus was performed when there was a high ventricular septal defect with a deformed aortic cusp. It would therefore appear that this possibility must be taken

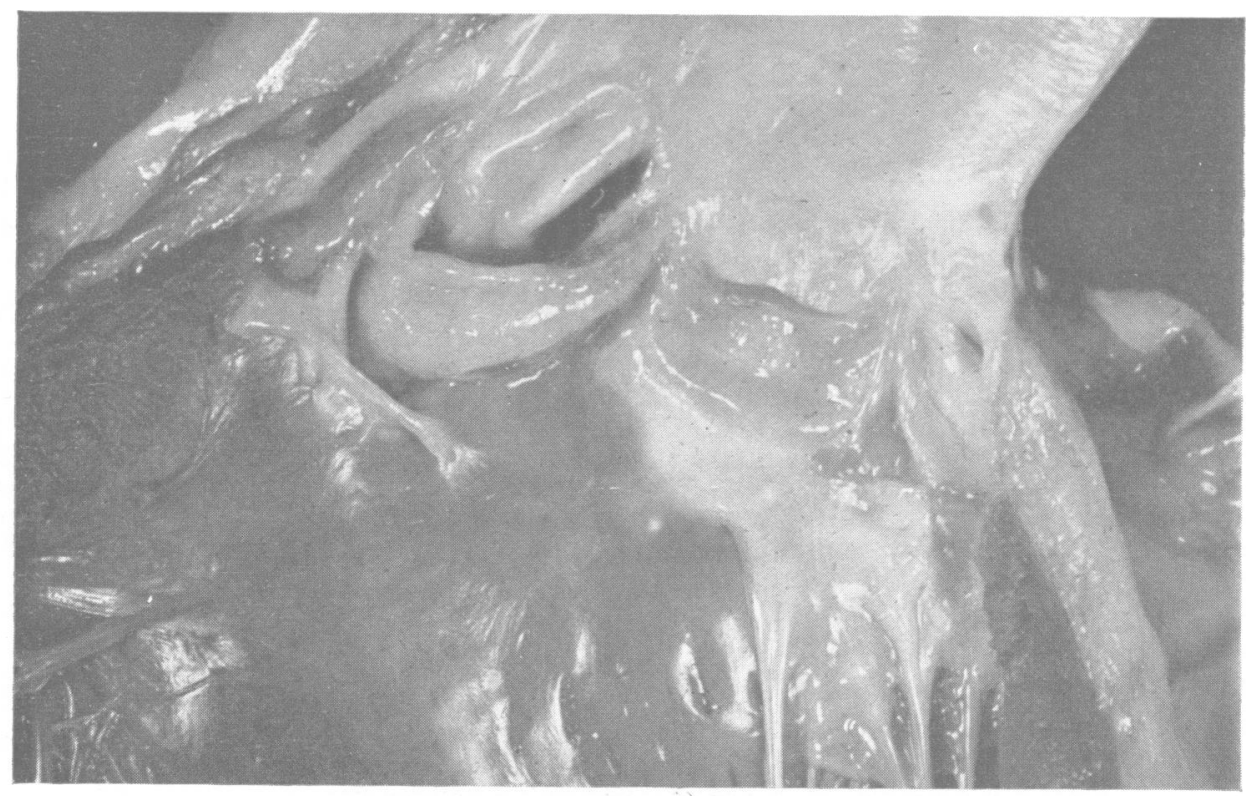

FIG. 1.-Photograph of the left ventricle, showing the anterior aortic cusp prolapsed into the ventricular septal defect. 
into consideration in the elucidation of what seems to be a characteristic continuous murmur in the pulmonary area, and cardiac catheterization studies performed in those cases where the murmur does not have the truly continuous quality of a patent ductus. However, even then the data may be insufficient to differentiate a patent ductus with free pulmonary regurgitation from a high ventricular septal defect of the type described in this paper unless intracardiac pressure recordings are made, as in the case reported by Morgan and Burchell (1950).

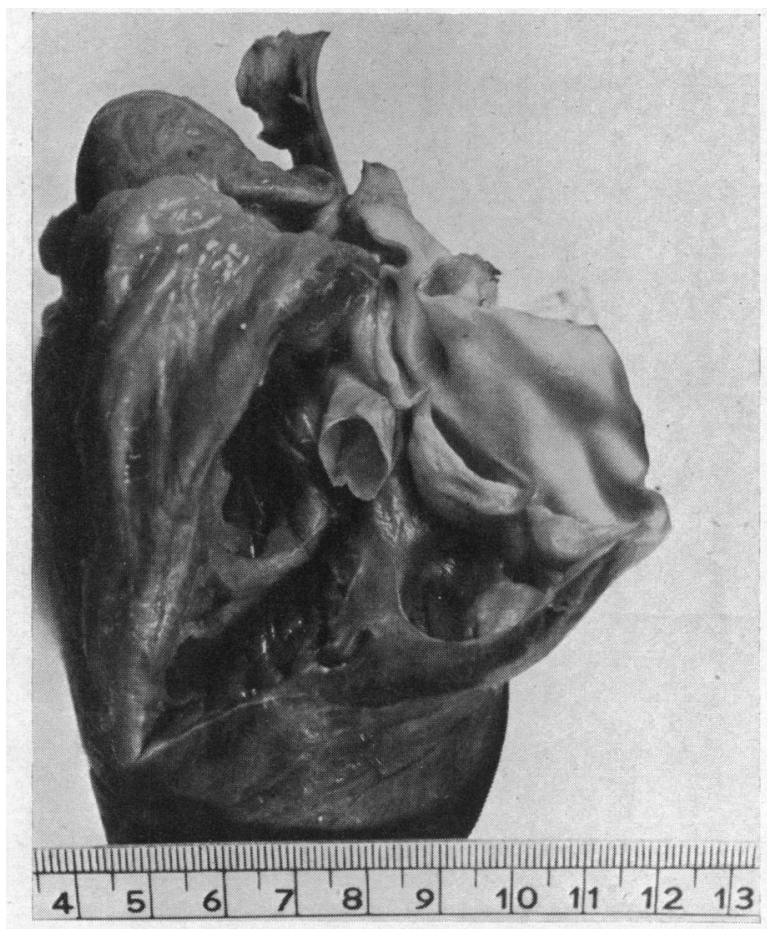

FIG. 2.-Photograph of right ventricle, showing the prolapsed anterior aortic cusp below the pulmonary valve. The rupture of the cusp at its apex is evident. (The specimen had been fixed in formalin when the photograph was taken.)

The prognosis in patients with ventricular septal defect is often considered to be good, but when there is an associated defect of the adjacent aortic cusp the prognosis is far more serious; there is an added strain on the heart from aortic insufficiency resulting in early or sudden cardiac failure.

In the case described above, the prolapse of the right aortic cusp had caused severe incompetence of the aortic valve, but this must have been a recent episode because none of the cusps showed any evidence of thickening or fibrosis. The præcordial pain was thought to be aortic in origin; the prolapse of the cusp probably caused acute tension of the wall of the aorta at its site of attachment. The presentation of a case with severe cardiac pain has so far not been recorded to the writer's knowledge.

\section{Summary}

A case is reported in which a continuous murmur in the pulmonary area led to a diagnosis of patent ductus arteriosus but at necropsy a high ventricular septal defect with prolapse of the adjoining aortic cusp through the defect was found. Attention is drawn to the uncommon presentation 
with cardiac pain and to the poor prognosis in this type of ventricular septal defect with a deformed aortic cusp.

\section{References}

Allen, A. C. (1941). Amer. Heart J., 21, 667.

Ascenzi, A., Comberiati, L., Episcopo, U., and Provenzale, L. (1951). Policlinico (sex. prat.), $58,833$.

Ash, R., and Murphy, L. (1950). J. Pediat., 37, 249.

Baylis, J. H., Campbell, M., Gilmore, H. R., and Hudson, R. (1955). Guy's Hosp. Rep., 104, 114.

Gasul, B. M., Fell, E. H., and Casas, R. (1951). Circulation, 4, 251.

Gross, R. E. (1952). Circulation, 5, 858.

(1953). Surgery of Infancy in Childhood. 1st ed., 813. W. B. Saunders Co., Philadelphia.

Hurst, W. W., and Schemm, F. R. (1948). Amer. Heart J., 36, 144.

Jones, A. M., and Langley, F. A. (1949). Brit. Heart J., 11, 325.

Laubry, C., and Pezzi, C. (1921). Traité des Maladies Congenitales du Coeur. J. B. Bailliére and fils, Paris.

$\longrightarrow$, Routier, D., and Soulié, P. (1933). Rev. Méd., Paris, 50, 439.

Morgan, E. H., and Burchell, H. B. (1950). Proc. Staff Meetings Mayo Clinic, 25, 69.

Porter, W. B. (1942). Amer. Heart J., 23, 468.

Soulié, P., Routier, D., and Bernal, P. (1949). Arch. Mal. Coeur, 42, 765.

Taussig, H. B. (1947). Congenital Malformations of the Heart. 1st ed., 400. The Commonwealth Fund, New York.

White, P. D., Chamberlain, F. L., Kelson, S. R. (1941). Ann. intern. Med., 15, 589.

Wood, P. (1950). Brit. med. J., 2, 639.

-, Magidson, O., and Wilson, P. A. O. (1954). Brit. Heart J., 16, 387. 